\title{
EFFECT OF COLD ROLLING ON LOW CYCLE FATIGUE BEHAVIOR OF A NEAR -ALPHA TITANIUM ALLOY
}

\author{
M. K. Tripathi ${ }^{1}$, N.C.Santhi Srinivas ${ }^{2}$, V. Singh $^{3}$ \\ ${ }^{2,3}$ Centre of Advanced Study, Department of Metallurgical Engineering, Indian Institute of Technology (Banaras Hindu \\ University), Varanasi-221 005, India \\ ${ }^{1}$ Department of Metallurgical and Materials Engineering, National Institute of Technology, Raipur-492010,India \\ ${ }^{2}$ Corresponding author : ncssrinivas.met@itbhu.ac.in
}

\begin{abstract}
Four cold reductions, viz. 2.5, 5, 7.5 and 10 percent are given to a near- $\alpha$ Titanium alloy Timetal 834, following solution treatment in $\alpha+\beta$ range and stabilization. $L C F$ tests were conducted at room temperature in total strain control mode at $\Delta \varepsilon_{1} / 2$ from $\pm 0.45 \%$ to \pm $1.05 \%$. Prior to LCF testing, gage section of the specimens was elecrtopolished to reveal the surface modifications, resulting from fatigue testing. It was observed that cold rolling considerably enhanced fatigue life of the alloy.
\end{abstract}

Key words: Titanium alloys; cold rolling; low-cycle fatigue; strain rate; Coffin-Manson relation $* * *$

\section{INRODUCTION}

Timetal 834 is one of the latest near- $\alpha$ commercial titanium alloy designed for high temperature application, up to service temperature of $873 \mathrm{~K}$, as compressor disc and blade of gas turbines of jet engines [1]. It has been established that the best combination of strength, creep resistance and low cycle fatigue life is exhibited in $\alpha+\beta$ treated condition, with $\sim 12$ volume percent primary $\alpha$ in the matrix of transformed $\beta$ with fine lamellar structure [2,3]. Dual slope in Coffin-Manson (C-M) relationship was observed by Singh et al [4] and was established to be associated with planarity of slip and its role in promoting crack initiation, at low strain amplitudes. Recently, it has been shown by Srinadh and Singh $[5,6]$ that bilinearity in $\mathrm{C}-\mathrm{M}$ relationship in this alloy, disappeared due to $15 \%$ cold rolling. The present work was undertaken to investigate the effect of different degrees of cold rolling on the low cycle fatigue behaviour of the alloy Timetal 834 . The material of the present investigation, Titanium alloy Timetal 834, was imported from M/s Timetal U.K and supplied by the project office (Materials), Kaveri Engine Programme, DRDO, Hyderabad, India. The alloy contained 5.8Al, 3.7Zr, 0.5Mo, $0.34 \mathrm{Si}, 4 \mathrm{Sn}, 0.7 \mathrm{Nb}, 0.06 \mathrm{C}, 0.105 \mathrm{O}, 0.0025 \mathrm{~N}, 0.004 \mathrm{H}$ and balance $\mathrm{Ti}(\mathrm{wt} \%)$. The material was received in the form of rods of $18 \mathrm{~mm}$ in diameter and in hot rolled, solution treated and stabilized condition. The solution treatment was given in the $(\alpha+\beta)$ phase field at $1283 \mathrm{~K}$ for 1 hour and the blanks were cooled in air. The solution treated blanks were aged at $973 \mathrm{~K}$ for 2 hours and cooled in air to stabilize the microstructure. This heat treatment is designated as AR in the present work. These blanks were subjected to different reductions such as $2.5 \%$ (AR-2.5CR), 5\% (AR-5CR), 7.5\%(AR-7.5CR) and 10\%(AR10CR) by rolling.
LCF tested specimens were electro polished using a solution of $59 \%$ Methanol, 35\% n-butanol and 6\% perchloric acid (volume percent), at 22.5 volts, using Timetal 834 cathode, at $255 \mathrm{~K}$. Tensile tests were carried out using a $50 \mathrm{kN}$ screw-driven Instron universal testing machine. LCF tests were carried out on a completely computer controlled servo hydraulic MTS testing machine (Model: 810 ) of $\pm 50 \mathrm{kN}$ capacity, with Test Star IIs control. Fully reversed $(\mathrm{R}=-1) \mathrm{LCF}$ tests were performed in air under total axial strain control till failure.

The low cycle fatigue behavior has been analyzed in terms of cyclic stress response and cyclic strain life relation and the results are compared with similar studies reported in the literature. Extensive optical microscopy of surface features before and after fatigue tests has been employed to understand the deformation mechanisms operating at different stages of the low cycle fatigue behavior of the material. The cyclic stress response of the material in the as heat treated condition and in the different cold rolled conditions was recorded. Since the total strain amplitude was kept constant in a test, the stress amplitude varied during the test with number of cycles. The stress variation with number of cycles at different strain amplitudes for the as heat treated, 5\% cold rolled, $7.5 \%$ cold rolled and 10\% cold rolled conditions shown in Fig. 1a, b, c \& d respectively.

Initially, some hardening takes place in all the conditions, irrespective of the initial condition. The material exhibits almost constant cyclic stress response during cyclic loading at the lowest strain amplitude but, shows continuous softening at higher strain amplitudes. Similar stress response occurs also in the $5 \%$ and $7.5 \%$ cold rolled material (Fig. 1b, c). It may be noted that cyclic stress response of the material is nearly 
identical for the as heat treated as well as for the differently cold worked conditions. It is interesting to observe that peak in stress response occurs at $\sim 10$ cycles in all the specimens, irrespective of their initial condition.
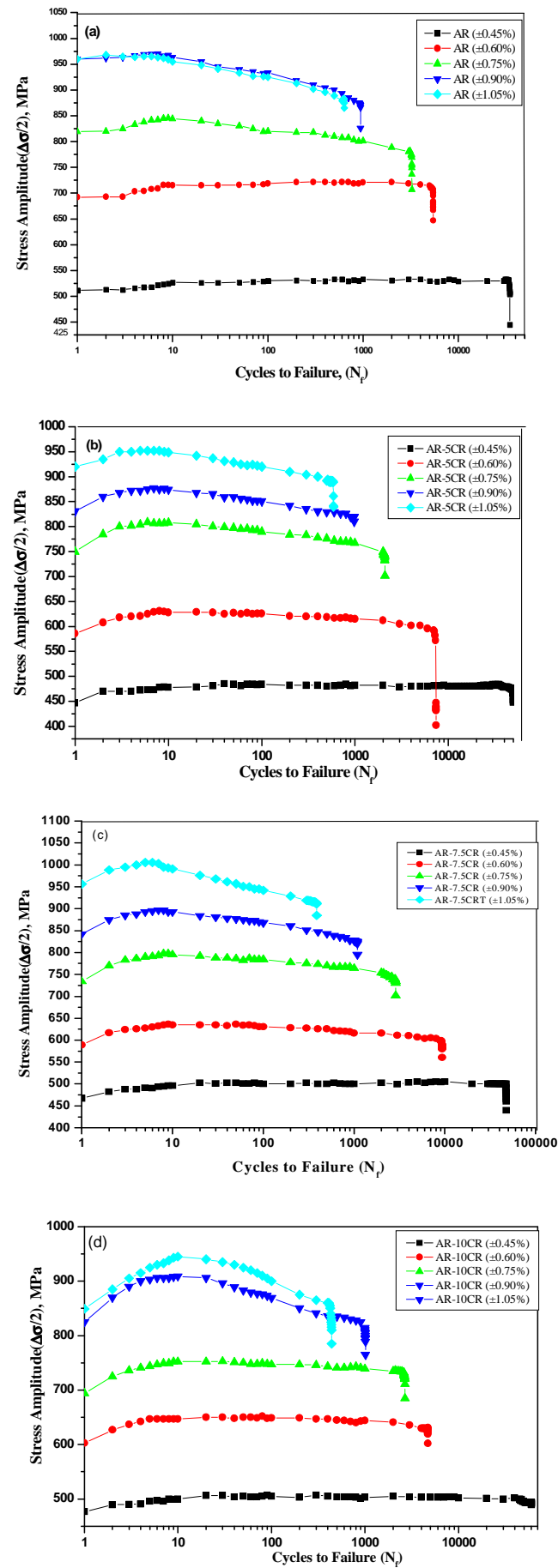

Fig.1: Cyclic stress response curves at different strain amplitudes at RT for Timetal 834 in (a) Heat treated (b) 5\% cold rolled (c) $7.5 \%$ cold rolled (d) $10 \%$ cold rolled conditions
The dependence of fatigue life (Nf) on plastic strain amplitude $(\Delta \varepsilon \mathrm{p} / 2)$ is usually expressed by the Coffin-Manson (C-M) relation:

$$
\Delta \varepsilon p / 2=\varepsilon^{\prime} f(2 N f) c
$$

Where $\Delta \varepsilon p / 2$ is plastic strain amplitude, $\varepsilon^{\prime} \mathrm{f}$ is fatigue ductility coefficient defined by the strain intercept at $2 \mathrm{Nf}=1,2 \mathrm{Nf}$ is number of strain reversals to failure and $\mathrm{c}$ is fatigue ductility exponent, which varies between -0.5 and -0.7 for many metals and alloys. The C-M plot for the different conditions is shown in Fig. 2. It is obvious that there is distinct dual slope in the as heat treated condition where as there is only single slope in the cold rolled conditions. Thus, it is seen that fatigue life of this material is significantly improved, at lower strain amplitudes, due to its cold rolling. This effect of cold rolling in improving fatigue life, particularly at low strain amplitudes is attributed to higher resistance of the material against the process of fatigue crack initiation.

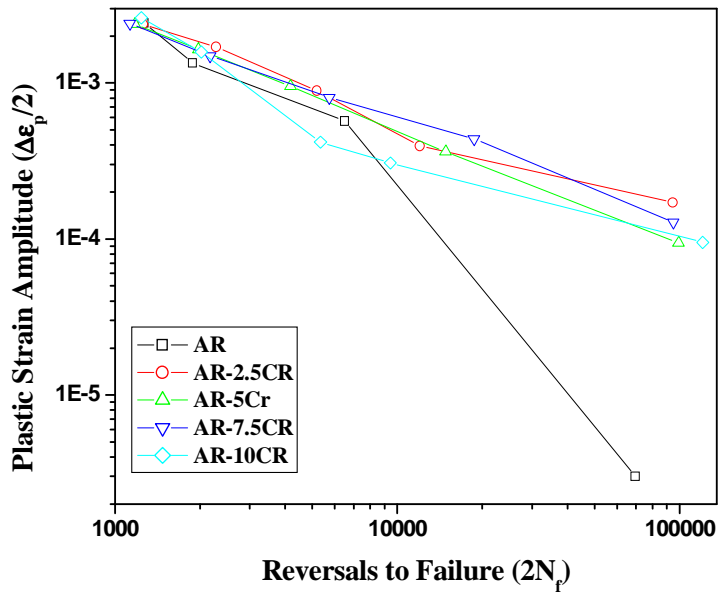

Fig. 2: Coffin-Manson plots for Timetal 834 in different conditions

The electro polished fatigue samples were tested at different strain amplitudes and the micro structural changes were recorded after completion of the fatigue tests. The changes in micro structural features of the as heat treated material, resulting from fatigue testing, are shown in Fig. 3. It may be seen that in the as heat treated condition there are widely spaced planar slip bands of essentially one orientation in some grains of the specimen tested at the lowest strain amplitude of $\pm 0.45 \%$ (Fig. 3b). Thus it is obvious that there is inhomogeneous deformation. In contrast, the features are significantly different in the specimens tested at higher strain amplitudes of $\pm 0.60 \%$ and $\pm 0.90 \%$ (Fig. 3c\&d). There is intersection of slip bands, due to activation of additional slip systems, at higher strain amplitudes. Thus the deformation is more homogeneous at the higher strain amplitudes. The 
development of long surface cracks may clearly be seen in Fig. $3 \mathrm{c} \& \mathrm{~d}$.

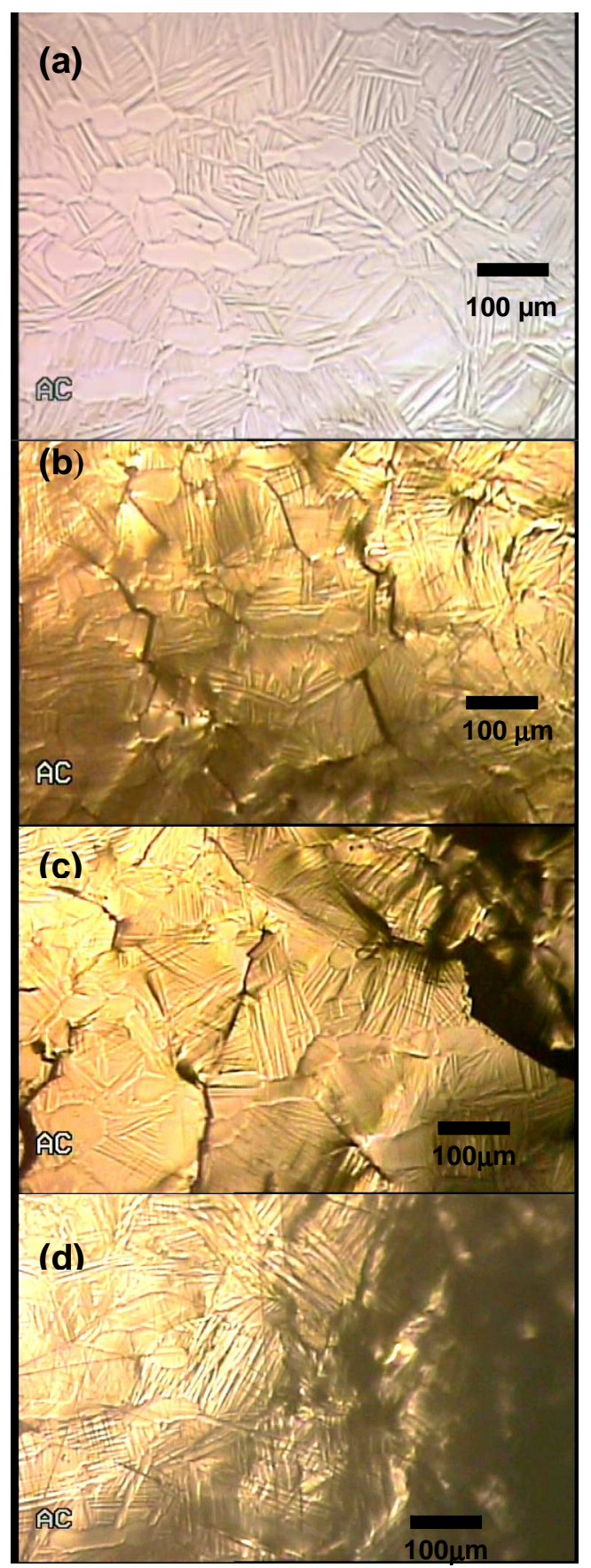

Fig. 3: Surface features of Timetal 834 in heat treated condition (a) without fatigue testing (b) fatigue tested at $\Delta \varepsilon_{\mathrm{t}} / 2$ : $\pm 0.45 \%$ (c) fatigue tested at $\Delta \varepsilon_{\mathrm{t}} / 2: \pm 0.60 \%$ (d) fatigue tested at $\Delta \varepsilon_{\mathrm{t}} / 2: \pm 0.90 \%$.
The surface features of the $7.5 \%$ cold rolled material, following fatigue testing are quite different (Fig. 4). The most striking feature is tortuosity of cracks, particularly in Fig. $4 \mathrm{a} \& \mathrm{~b}$. It leads to high fatigue life of cold rolled samples, even at low strain amplitudes.

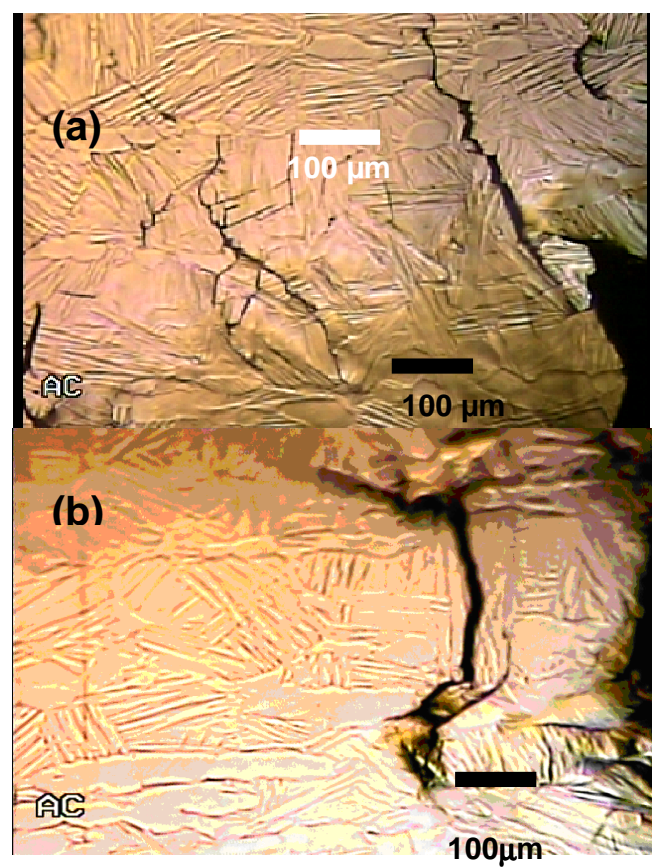

Fig. 4: Surface features of Timetal 834 in $7.5 \%$ cold rolled condition (a) fatigue tested at $\Delta \varepsilon_{t} / 2: \pm 0.60 \%$ (b) fatigue tested at $\Delta \varepsilon_{\mathrm{t}} / 2: \pm 0.90 \%$

\section{CONCLUSIONS}

The present investigation shows that cold rolling of the alloy Timetal 834 has significant effect on its low cycle fatigue behaviour. While there is dual slope in the C-M plot of the as heat treated material there is only single slope in the cold worked material. It is seen that even low degree of cold working $(\sim 5 \%)$ is effective in improving fatigue life of the alloy at low strain amplitudes and consequent elimination of bilinearity from the C-M plot.

\section{ACKNOWLEDGEMENTS}

Authors are thankful to Project Director, Project Office (Materials), Kaveri Engine Programme, Defence Research and Development Organization, Hyderabad, India for providing the experimental material. Financial support given by University Grants Commission, India, to one of the authors is also gratefully acknowledged. 


\section{REFERENCES}

[1] S.Hardt, H.J.Mair, H J Christ, Int. J. Fatigue, 21 (1999), 779

[2] S.Hardt, HJ Mair, H.J. Christ, Proc Low Cycle fatigue and Elastic-plastic behaviour of materials, Elsevier, Amesterdam (1998), 9

[3] D. F. Neal, Titanium Sci \& Tech: Proc. Fifth Int.conf. on Titanium Congress- centre, Munich, FRG, September 10-14, 1984, DGM-Oberusal (1985),2419

[4] Nidhi Singh, Gouthama and Vakil Singh, Mater. Sci. Engg. A, 325, (2002), 324

[5] K.V. Sai Srinadh and Vakil Singh, Trans Indian Inst. Metals, 57(6), (2004), 431

[6] K.V. Sai Srinadh and Vakil Singh, Metallurgical and Materials Transactions A, 38 (8), (2007), 1868 